\title{
Adaptation to prismatically induced curvature with nonvisible arm movements'
}

\author{
CLARKE A. BURNHAM \\ UNIVERSITY OF TEXAS AT AUSTIN
}

\begin{abstract}
Subjects, wearing prism spectacles to induce curvature, shot a pistol at a target moving in an apparently horizontal path. The Ss were able to hit the target without having to view their arms, hands, or the pistol. Adaptation occurred only in a condition requiring the learning of new afferentefferent associations. The results are consistent with those of a prior shooting gallery study and were interpreted as supporting the efferent readiness theory of perception.
\end{abstract}

Festinger has recently proposed that the conscious experience of perception is determined by efferent readiness activated by afferent visual stimulation (Festinger, Burnham, Ono, \& Bamber, 1967). This efferent readiness theory of perception has been supported by three experiments concerned with adaptation to the curvature produced by the wearing of prism spectacles (Festinger et al, 1967). In each of these experiments $\mathrm{Ss}$ in conditions requiring the issuance of efference concerned with the contour adapted more than Ss in conditions requiring similar active movements but not the learning of new afferent-efferent associations. Thus Ss shooting at a moving target with an infrared ray adapted whereas Ss shooting with a visible light ray did not adapt.

The results of these experiments suggest that Held's model of adaptation (Held, 1961; Held \& Rekosh, 1963) is too gross. Apparently not all active movements and the resultant atypical visual re-afference produce adaptation to curvature. However, it is possible that differential attention to the re-afferent stimulation in the learning conditions of the Festinger et al studies caused the differences in adaptation. The Ss in both conditions of the shooting gallery study were told to sight, but only the Ss shooting with the infrared ray needed to sight to hit the target. The necessity to sight and the resultant atypical visual re-afference from the arm and hand may have facilitated adaptation.

The present investigation eliminated the possibility of differential visual re-afference from the arm and hand by preventing Ss from seeing their arms and hands. As in the prior shooting gallery study, one condition was designed to produce the learning of new afferentefferent associations whereas the other was designed to minimize such learning.

Method

The apparatus and procedure used in this study are similar to those reported for Experiment 3 in Festinger et al. The Ss shot a pistol emitting a continuous light ray at a target moving back and forth along a horizontal track at a rate of $1.5 \mathrm{ft}$ per sec. When the light ray hit the center of the target, a photocell and relay circuit activated a buzzer and a time clock. While shooting Ss wore $30 \mathrm{deg}$ prism spectacles with the base of the prism mounted upwards.

In both the learning and nonlearning conditions the small photocell target, $1 \mathrm{~cm} \times 1 \mathrm{~cm}$, was located in the center of a white rectangle, 7 in. $x 10$ in. In the learning condition the portion of this rectangle immediately surrounding the photocell was covered by a black ellipse with a major axis of 5 in. and a minor axis of $3-1 / 2$ in. A blue filter was placed over the pistol barrel, and a red filter was placed on the front of the prism spectacles. With this combination of filters Ss were able to see the light ray when the pistol was aimed at the white rectangle but unable to see it when the pistol was aimed at the black ellipse.

The large white rectangle enabled Ss to find the general position of the target without having to aim. Once having found the target area, Ss shooting with the all-white rectangle could use the reflection from it to guide their arm movements while trying to stay on the photocell. The Ss shooting at the target with the black inner ellipse could also use the reflection from the white rectangle to see when they were near the target. However, when attempting to remain on the photocell they had to issue efference which was concerned with the path of the target's movement.

The S shot from a seated position and was instructed to hold the pistol so that he was unable to see it. Head movements were prevented by a biteboard. The center of the track was 56 in. in front of $S$ and the visible portion of it subtended an angle of $80 \mathrm{deg}$. The track on which the target moved could be adjusted by $S$ to appear straight. When $\mathrm{S}$ was shooting, E set the track to appear straight to avoid a change in curvature due to the Gibson normalization effect (Gibson, 1933).

The experimental procedure was as follows. The $S$ was instructed in the method of shooting and given a minute of practice without the spectacles. The technique for adjusting the track to level was explained and practiced, and the initial measurements of straight with plain glass spectacles and with prism spectacles were taken. After these initial measurements, S, wearing the prism spectacles, watched the target move back and forth along the apparently straight track for a 5 min period. This viewing period was followed by another series of settings with the prisms. It was felt that the settings following this exposure to the 
various distortions produced by the prism spectacles would be a more reliable estimate of apparently straight from which to calculate the adaptation caused by shooting. The $\mathrm{S}$ then shot for four $6 \mathrm{~min}$ periods, each followed by a series of settings made with the prisms and a rest period of $5 \mathrm{~min}$. After the final settings with the prisms, $S$ made a series of settings with the plain glass spectacles to test for an aftereffect.

The Ss were 24 undergraduate male psychology students. Approximately half were volunteers from an advanced course and were paid for participation. The others participated to fulfill a requirement for an introductory course. Each of two Es ran approximately half the Ss in each condition.

Resulis

Analyses by $t$ tests of the differences in initial settings with and without the prisms and in the adaptation and aftereffect between the Ss in each condition who were run by each $\mathrm{E}$ resulted in no significant differences. Therefore the $\mathrm{E}$ variable was not included in subsequent analyses.

The Ss assigned to the two conditions did not differ in their settings before the introduction of the experimental manipulation in the shooting periods. The average magnitude of prismatically induced curvature was $19.89 \mathrm{~cm}$.

The major experimental data are the changes between the settings after the viewing period and those following the four shooting periods. These change scores were analyzed by a 2 by 4 analysis of variance design with experimental conditions and periods as the variables. There was a significant difference between the two conditions in the magnitude of adaptation $(F=6.75, d f=1 / 22$, $p<0.05)$. The Ss who shot at the target with the black ellipse adapted an average of $0.47 \mathrm{~cm}$. The corresponding change for Ss who shot at the all-white target was $-0.12 \mathrm{~cm}$. The average adaptive change for $\mathrm{Ss}$ in the learning condition differs significantly from zero $(t=3.31, d f=11, p<0.01)$; the change for $S s$ in the nonlearning condition is not significantly different from zero $(t=0.67, d f=11)$. Neither the trial effect nor the interaction of conditions and trials was significant.

There was no difference between the conditions in the magnitude of the aftereffect. For neither group did the average of the final settings differ by more than $0.01 \mathrm{~cm}$ from the average of the initial settings.

There was, as would be expected, a very substantial difference in the shooting performance of the two groups. The Ss who could see the light ray at all times remained on the photocell an average of $180 \mathrm{sec}$ of each $6 \mathrm{~min}$ shooting period. The Ss who were unable to see the light in the immediate area of the photocell remained on target an average of only $88 \mathrm{sec}$.

\section{Discussion}

As in the prior shooting gallery study, Ss who were required to learn a new afferent-efferent association adapted to the prismatically induced curvature whereas Ss who were continuously able to guide their motor movements visually did not adapt. The Ss in the learning condition of this study, unlike those in the prior shooting gallery study, did not need to see their arms and hands while shooting. Therefore, there was no possibility for atypical visual re-afference from the arm and hand to produce adaptation. Both groups of Ss made similar arm and hand movements which roughly equated the proprioceptive inflow from the musculature.

The lack of a significant difference between the conditions in aftereffect was unexpected. It is possible that the new afferent-efferent associations established in this experimental situation decay rapidly. The aftereffect measurements were begun about 6 min after the final shooting period. Such a decay might also account for the lack of an increase in adaptation across the shooting periods. It is also possible that the new afferent-efferent associations were conditioned to a particular head orientation. The biteboard was placed at a different angle when $S$ wore the prisms than when he wore the plain glass spectacles to compensate for the prism displacement effect.

The experimental manipulation in this investigation was relatively small, namely the presence of a 5 in. $x 31 / 2$ in. nonreflecting ellipse surrounding the target. This ellipse prevented $\mathbf{S}$ from visually guiding his motor activity when near the target and thus required that he learn to issue efference concerned with the contour of the target's movement. The results of this study further support the theory that what one sees is determined by the efferent readiness activated by the visual input.

\section{References}

FESTINGER, L., BURNHAM, C. A., ONO, H., \& BAMBER, D. Efference and the conscious experience of perception. $J$. exp. Psychol., Monogr. Suppl, 1967, 74, 4 (Whole No. 637).

GIBSON, J. J. Adaptation, after-effect and contrast in the perception of curved lines. J. exp. Psychol., 1933, 16, 1-31.

HELD, R. Exposure-history as a factor in maintaining stability of perception and coordination. J. Nerv. Ment. Dis., 1961, 132, 26-32.

HELD, R., \& REKOSH, J. Motor-sensory feedback and the geometry of visual space. Science, 1963, 141, 722-723.

Note

1. Charles Berg assisted the author in preparing the apparatus and pretesting the conditions. Charles Ervin assisted with the experimentation. 